\title{
A Birth-cohort testing intervention identified hepatitis $c$ virus infection among patients with few identified risks: a cross- sectional study
}

William N. Southern ${ }^{1,2,6^{*}}$, Brianna Norton ${ }^{2,3}$, Meredith Steinman $^{2,3}$, Joseph DeLuca ${ }^{2,3}$, Mari-Lynn Drainoni ${ }^{4}$, Bryce D. Smith ${ }^{5}$ and Alain H. Litwin²,3

\begin{abstract}
Background: International guidelines and U.S. guidelines prior to 2012 only recommended testing for hepatitis C virus (HCV) infection among patients at risk, but adherence to guidelines is poor, and the majority of those infected remain undiagnosed. A strategy to perform one-time testing of all patients born during 1945-1965, birth cohort testing, may diagnose HCV infection among patients whose risk remains unknown. We sought to determine if a birth-cohort testing intervention for HCV antibody positivity helped identify patients with fewer documented risk factors or medical indications than a pre-intervention, risk-based testing strategy.

Methods: We used a cross-sectional design with retrospective electronic medical record review to examine patients identified with $\mathrm{HCV}$ antibody positivity (Ab+) during a pre-intervention (risk-based) phase, the standard of care at the time, vs. a birth-cohort testing intervention phase. We compared demographic and clinical characteristics and HCV risk-associated factors among patients whose HCV Ab + was identified during the pre-intervention (risk-based testing) vs. post birth-cohort intervention phases. Study subjects were patients identified as HCV-Ab + in the baseline (risk-based) and birth-cohort testing phases of the Hepatitis C Assessment and Testing (HepCAT) Project.

Results: Compared to the risk-based phase, patients newly diagnosed with HCV Ab + after the birth-cohort intervention were significantly less likely to have a history of any substance abuse ( $30.5 \%$ vs. $49.5 \%, p=0.02$ ), elevated alanine transaminase levels of $>40 \mathrm{U} / \mathrm{L}(22.0 \%$ vs. $46.7 \%, p=0.002)$, or the composite any risk-associated factor (55.9\% vs. $79.0 \%, p=0.002$ ).

Conclusions: Birth-cohort testing is an useful strategy for identifying previously undiagnosed HCV Ab + because it does not require providers ask risk-based questions, or patients to disclose risk behaviors, and appears to identify HCV $\mathrm{Ab}+$ in patients who would not have been identified using a risk-based testing strategy.
\end{abstract}

Keywords: Hepatitis C virus, Screening, Testing strategies, Risk assessment

\footnotetext{
* Correspondence: wsouther@montefiore.org

${ }^{1}$ Division of Hospital Medicine, 111 East 210th Street, Bronx 10467 NY, USA

${ }^{2}$ Montefiore Medical Center, 111 East 210th Street, Bronx, NY 10467, USA

Full list of author information is available at the end of the article
} 


\section{Background}

An estimated 3.2 million persons are infected with the hepatitis $\mathrm{C}$ virus (HCV) in the U.S $[1,2]$. In the absence of testing, care, and treatment, $\mathrm{HCV}$ infection is predicted to cause 1.5 million cases of cirrhosis and contribute to 900,000 deaths over the lifetime of infected persons [3]. Curative treatment for $\mathrm{HCV}$ infection is available, and early testing is associated with early entry into care [4-8]. Previous U.S. and many international guidelines recommend testing patients at risk for $\mathrm{HCV}$ infection including those with a history of injection drug use, recipients of transfusions or organ transplants, and those with elevated alanine aminotransferase (ALT) levels [7-12]. However, providers are often non-adherent to riskbased testing guidelines [13], and the majority of those infected remained undiagnosed [13-15].

Data have demonstrated that approximately $77 \%$ of all $\mathrm{HCV}$-infected persons in the U.S. were born between 1945 and 1965 [16] and adults in this cohort have a $\mathrm{HCV}$ infection prevalence of $3.2 \%$, approximately five fold higher than other adults outside of this age cohort [17]. Therefore, in the U.S. one-time testing of all patients born during 1945-1965, birth-cohort testing, is now recommended by the Centers for Disease Control and Prevention and the US Preventive Services Task Force in addition to risk-based testing [18-20]. In addition, it is possible that a birth-cohort-based testing strategy is more effective for identification of HCVinfected patients who have no known risk factors or medical indications for HCV testing. To investigate this, we examined the characteristics and risk factors of $\mathrm{HCV}-\mathrm{Ab}+$ persons who were identified during a preintervention phase when risk-based testing was the standard of care vs. after a birth-cohort testing intervention. We hypothesized that patients identified as HCV$\mathrm{Ab}+$ using a birth-cohort testing strategy would be less likely to have documented risk factors or medical indications as compared to patients identified as $\mathrm{HCV}$ $\mathrm{Ab}+\mathrm{by}$ traditional risk-based testing strategy.

\section{Methods}

\section{Study setting}

The study was conducted at three community-based primary care clinics affiliated with Montefiore Medical Center, a regional healthcare system including four hospitals and twenty three outpatient sites, located in the Bronx, New York. The estimated prevalence of $\mathrm{HCV} \mathrm{Ab}+$ in the population served by the study sites is $7.7 \%[13]$.

\section{Study design and population}

Study subjects were drawn from the baseline (riskbased testing) and birth-cohort testing phases of the Hepatitis C Assessment and Testing Project (HepCAT), a cross-sectional intervention study investigating a birth cohort testing strategy for $\mathrm{HCV} \mathrm{Ab}+$, described previously $[13,21,22]$. In short, patients were eligible to be included in the risk-based testing group if they had a clinic visit at one of the study sites during the baseline phase of HepCAT (1 January 2008 to 29 February 2008). Patients were eligible to be included in the birth-cohort testing group if they were tested at a clinic visit during the birth-cohort phase of HepCAT (9 March 2009-30 June 2009). The birth-cohort intervention phase was conducted for four months to maximize the number of patients who were tested for HCV. Patients were considered newly-identified $\mathrm{HCV}-\mathrm{Ab}+$ and included in this study if they had no previous record of $\mathrm{HCV} \mathrm{Ab+,}$ and tested positive for HCV antibody, at any hospital or site in the Montefiore system, within 2 years before or 90 days after the qualifying clinic visit for the baseline phase or within 90 days after the clinic visit date in the birth-cohort (intervention) phase. Retrospective electronic medical record (EMR) review was used to examine clinical characteristics and $\mathrm{HCV}$ risk factors of patients identified with $\mathrm{HCV} \mathrm{Ab}+$ during the pre-intervention phase (when risk-based testing was the standard of care), vs. after a birth-cohort testing intervention.

\section{Data extraction}

For each research subject we extracted data from Montefiore's Clinical Information System including demographic information associated with the qualifying clinic visit, and clinical information dating back to March 1997, from any contacts the subjects had with a Montefiore hospital or outpatient site. This included inpatient and outpatient ICD-9 diagnosis codes, prescription and inpatient medication records, and laboratory testing results.

\section{Birth-cohort vs. Risk-based testing}

During the baseline (pre-intervention) phase of the parent study most patients tested for HCV antibody had a documented risk factor or medical indication suggesting that providers were following risk-based testing recommendations for $\mathrm{HCV}$ testing [13]. During the birthcohort phase, a reminder sticker was placed on each progress note for every visit (Fig. 1). The reminder recommended that providers order an $\mathrm{HCV}$ antibody test for all patients born during 1945-1964, regardless of any other identified risk.

\section{Markers of risk/definitions}

Because we were unable to directly measure primary risks for $\mathrm{HCV}$ exposure (e.g. injection drug use) we measured factors/markers that may be indicative of being at increased risk for $\mathrm{HCV}$ exposure and other demographic characteristics (such as age and race/ethnicity) previously 


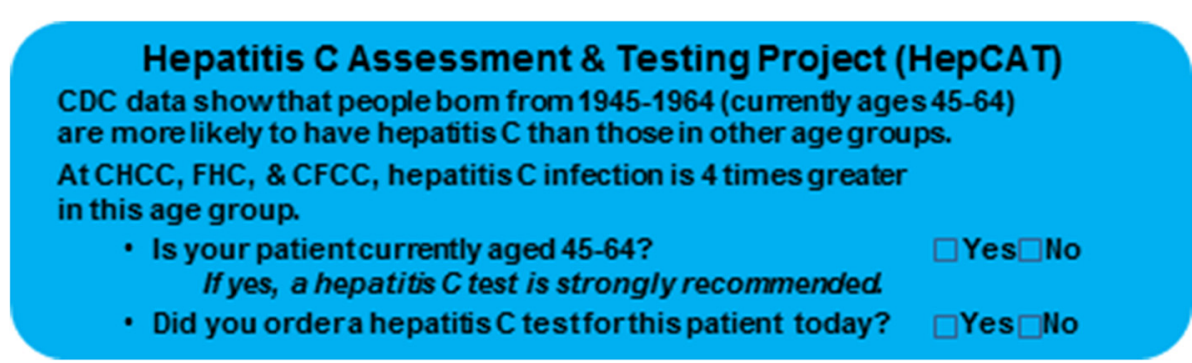

Fig. 1 The birth-cohort reminder sticker placed in the chart during the birth-cohort testing phase of the study

shown to be associated with $\mathrm{HCV}$ antibody positivity. A factor/marker for testing was considered present if it appeared anytime in the medical record before the index clinic visit. Independent variables included age, sex, race/ ethnicity, any substance abuse (coded as present if an ICD-9 code for substance abuse/dependence or a positive urine toxicology for amphetamines, barbiturates, cocaine, or methadone was recorded), HIV infection (ICD-9 code or positive antibody test confirmed by western blot), sexually transmitted infection [23, 24] (ICD-9 code indicating gonorrhea or chlamydia or positive gonorrhea or chlamydia PCR probe), alcohol abuse [25, 26] (ICD-9 code for alcohol dependence or alcohol-related liver disease, or a serum alcohol level $\geq 80 \mathrm{mg} / \mathrm{dl}$ ), cirrhosis (ICD-9 code for cirrhosis), end stage renal disease (ICD-9 code for endstage renal disease or procedure code for hemodialysis), psychiatric disease [27, 28] (ICD-9 code for affective disorder, anxiety disorder, schizophrenia, or psychosis), and ALT elevation (using the highest ALT value reported, considered elevated if $>40 \mathrm{U} / \mathrm{L})[29,30]$. In addition, we examined a composite variable, any riskassociated factor, which included history of any of the aforementioned variables, substance abuse, HIV infection, sexually transmitted infection, alcohol abuse, cirrhosis, end stage renal disease, history of psychiatric illness, or ALT $>40 \mathrm{U} / \mathrm{L}$. Each diagnosis was represented by a group of ICD-9 codes using the classification system of the Healthcare Cost and Utilization Project of the Agency for Healthcare Research and Quality system [31] (Appendix: Table 2).

\section{Statistical analysis}

To determine if patients identified as $\mathrm{HCV} \mathrm{Ab}+$ during the pre-intervention vs. post intervention phases had different risk profiles, we compared demographic and $\mathrm{HCV}$ risk characteristics between the two groups using $t$-tests, Chi-squared and Fisher's exact tests, as appropriate. A $p$-value $<0.05$ was considered significant.

STATA/IC software, version 10.0, (StataCorp, College Station, TX) was used for all data management and statistical analysis. The Institutional Review Boards of Boston
University Medical Center and Montefiore Medical Center approved this study.

\section{Results}

The study sample included 164 patients who were newly identified $\mathrm{HCV} \mathrm{Ab+.} \mathrm{The} \mathrm{study} \mathrm{population} \mathrm{mean} \mathrm{age}$ was $49.9+/-12.0$ years, $57.9 \%$ male, $60.4 \%$ Latino, $26.2 \%$ non-Hispanic Black and $4.9 \%$ non-Hispanic White. Of these, 105 patients $(64.0 \%)$ were identified $\mathrm{HCV} \mathrm{Ab}+$ during the risk-based phase and 59 patients (36.0 \%) during the birth-cohort phase. Patients identified during the birth-cohort phase were less likely to be male ( $49.1 \%$ vs. $62.9 \%, p=0.09)$, but the difference was not significant. The patient groups were similar with respect to age and racial/ethnic characteristics.

Compared to the risk-based phase, patients identified during the birth-cohort phase were significantly less likely to have a documented history of substance abuse (30.5\% vs. $49.5 \%, p=0.02$ ), an ALT measurement $>40$ $\mathrm{U} / \mathrm{L}(22.0 \%$ vs. $46.7 \%, p=0.002)$, or the composite any risk-associated factor (55.9 \% vs. $79.0 \%, p=0.002$ ). In addition, other co-morbidities were less common in the birth-cohort group, including HIV infection $(10.2 \%$ vs. $19.0 \%, p=0.13)$, cirrhosis ( $0.0 \%$ vs. $4.7 \%, p=0.16)$, and history of psychiatric illness ( $11.9 \%$ vs. $21.9 \%, p=0.11)$, but the differences were not significant (Table 1).

\section{Discussion}

We found that patients who were newly identified as $\mathrm{HCV} \mathrm{Ab}+$ after a birth-cohort testing intervention were significantly less likely to have a documented indication for HCV testing than patients identified during the riskbased testing phase. Specifically, birth-cohort phase patients were significantly less likely to have a documented history of substance abuse or elevated serum ALT levels. In addition, it was less common for birth-cohort phase patients to have one of several diagnoses that might trigger and HCV test including of HIV infection, cirrhosis, or a history of psychiatric illness. Our study highlights an important limitation of a risk-based testing strategy and suggests that providers using a birth-cohort testing strategy may find $\mathrm{HCV}$ infection among a number of 
Table 1 Characteristics of Patients Identified HCV Positive using Risk-based vs. Birth-cohort Strategies

\begin{tabular}{|c|c|c|c|}
\hline & Risk-based phase & Birth-cohort phase & \\
\hline & $n=105(\%)$ & $n=59(\%)$ & $p$ value \\
\hline Age & $50.5 \pm 10.8$ & $48.9 \pm 12.0$ & 0.45 \\
\hline Male & $66(62.9)$ & $29(49.2)$ & 0.09 \\
\hline Race/Ethnicity & & & 0.99 \\
\hline White & $5(4.8)$ & $3(5.1)$ & 0.99 \\
\hline Black & $27(25.7)$ & $16(27.1)$ & 0.84 \\
\hline Hispanic & $64(61.0)$ & $35(59.3)$ & 0.84 \\
\hline Other/Unknown & $9(8.6)$ & $5(8.5)$ & 0.98 \\
\hline Insurance & & & 0.66 \\
\hline Medicare & $5(4.8)$ & $5(8.5)$ & 0.34 \\
\hline Medicaid & $83(79.0)$ & $42(71.2)$ & 0.26 \\
\hline Commercial & $8(7.6)$ & $5(8.5)$ & 0.85 \\
\hline Self & $9(8.6)$ & $7(11.9)$ & 0.49 \\
\hline History Substance Abuse & $52(49.5)$ & $18(30.5)$ & 0.02 \\
\hline HIV Infection & $20(19.0)$ & $6(10.2)$ & 0.13 \\
\hline History STI & $2(1.9)$ & $0(0.0)$ & 0.54 \\
\hline Alcohol Abuse & $4(3.8)$ & $1(1.7)$ & 0.65 \\
\hline Cirrhosis & $5(4.7)$ & $0(0.0)$ & 0.16 \\
\hline End Stage Renal Disease & $0(0.0)$ & $2(3.4)$ & 0.13 \\
\hline History Psychiatric IIIness & $23(21.9)$ & $7(11.9)$ & 0.11 \\
\hline $\mathrm{ALT}>40 \mathrm{U} / \mathrm{L}$ & $49(46.7)$ & $13(22.0)$ & 0.002 \\
\hline Any Factor ${ }^{b}$ & $83(79.0)$ & $33(55.9)$ & 0.002 \\
\hline
\end{tabular}

patients without an identified risk or clinical indication for testing whose infection would not have been found otherwise.

Though risk-based testing is important given the high prevalence of disease among patients with known risk factors, this testing strategy has had limited effectiveness. The majority of the HCV-infected individuals in the United States are still unaware of their infection 25 years after the discovery of the hepatitis $C$ virus $[14,15]$. Riskbased testing is limited because it is dependent on the physician's willingness and time to inquire about risk, as well as a patient's ability to recall risk exposure, such as a blood transfusion prior to 1992, or comfort with disclosing risk, such as injection drug use (IDU) [32]. As a result, risk-based testing may not identify $\mathrm{HCV}$-infected patients despite exposure to risk at some point in their lives. It is likely that most of the patients in the study were exposed to $\mathrm{HCV}$ through injection drug use [9]. However, during the birth-cohort intervention phase the vast majority of patients (41 of 59) did not have substance abuse as an identified risk in their medical chart, highlighting the limitations of risk-based testing. A birth-cohort only testing strategy also has limitations: it would fail to identify infection among young people who inject drugs, a critical group in the ongoing spread of $\mathrm{HCV}$ infection. For this reason it is likely that a combination of risk-based and birth-cohort testing is optimal in the US.

In addition, elevated ALT levels may be a common reason for testing a patient for $\mathrm{HCV}$, but many patients with $\mathrm{HCV}$ infection do not have elevated liver enzymes and their infection may be missed [33, 34]. Our results suggest that the birth-cohort testing strategy is more likely to identify $\mathrm{HCV}-\mathrm{Ab}+$ individuals without an elevated ALT level. This study demonstrated that individuals living with $\mathrm{HCV}$ who do not have known $\mathrm{HCV}$ risks may be identified through birth-cohort testing. These individuals will now be able to receive confirmatory testing, and if appropriate, proper counseling, care, and treatment for their infection.

Now more than ever, identification of all HCV-positive individuals is crucial. With the advent of highly effective, tolerable and easily administered HCV medications, we have an opportunity to halt rising morbidity and mortality, and there is long-term potential for eradication of $\mathrm{HCV}$ disease [35]. Effective testing remains the first step in this 
process. As shown in this study, birth-cohort testing may help identify those without known risk factors, improving the detection rates and treatment opportunity for a subset of those currently unaware of their infection. Studies have shown that birth-cohort screening is cost-effective, even in the era of expensive direct-acting antivirals [36], and models have predicted that implementation of this screening strategy could avert 78,000121,000 deaths, and over 10,000-19,000 liver transplants among those living with $\mathrm{HCV}$ who remain undiagnosed [36, 37].

Our study has several limitations. First, the CDC and USPSTF birth-cohort testing guidelines were developed based on HCV prevalences in the U.S and may not be applicable outside the U.S. Whether there are birthcohort populations outside of the U.S. that would benefit from testing is unknown. Next, we measured HCV antibody positivity, not RNA confirmed $\mathrm{HCV}$ infection. In addition, our risk-associated factors were primarily defined by ICD-9 codes which may have resulted in misclassification. Although we believe that this classification is likely non-differential and did not bias our results, we cannot confirm that this is so. Next, we did not measure the adherence to the intervention or the durability of the intervention. In addition, we were not able to directly measure risks for $\mathrm{HCV}$ infection (e.g., injection drug use) and so instead measured surrogates for risk that, if noted, might provoke HCV testing. Finally, because our sample size was relatively small we were unable to perform multivariate analyses.

\section{Conclusions}

The majority of HCV-infected persons remain unidentified. Now that curative therapy is available, uptake of Centers for Disease Control and Prevention and US Preventive Services Task Force HCV screening guidelines for birth cohort testing is critical so that HCV-infected individuals with no known risk factors or apparent clinical indications for testing can be identified.

\section{Appendix}

Table 2 ICD-9 Code Diagnosis Grouping

\begin{tabular}{ll}
\hline Diagnosis grouping & ICD-9 Codes \\
\hline Substance Abuse & $304.0,304.00,304.01,304.02,304.03,304.1,304.10,304.11,304.12,304.13,304.2,304.20,304.21,304.22,304.23,304.3,304.30$, \\
& $304.31,304.32,304.33,304.4,304.40,304.41,304.42,304.43,304.5,304.50,304.51,304.52,304.53,304.6,304.60,304.61,304.62$, \\
& $304.63,304.7,304.70,304.71,304.72,304.73,304.8,304.80,304.81,304.82,304.83,304.9,304.90,304.91,304.92,304.93,305.2$, \\
& $305.20,305.21,305.22,305.23,305.3,305.30,305.31,305.32,305.33,305.4,305.40,305.41,305.42,305.43,305.5,305.50,305.51$, \\
& $305.52,305.53,305.6,305.60,305.61,305.62,305.63,305.7,305.70,305.71,305.72,305.73,305.8,305.80,305.81,305.82,305.83$, \\
& $305.9,305.90,305.91,305.92,305.93,292.0,292.1,292.11,292.12,292.2,292.8,292.81,292.82,292.83,292.84,292.85,292.89$, \\
& $292.9,648.3$
\end{tabular}

HIV

Sexually Transmitted Infection

Alcohol Abuse

Cirrhosis

End Stage Renal Disease

Psychiatric Diagnosis
042, 042.0, 042.1, 042.2, 042.9, 043.0, 043.1, 043.2, 043.3, 043.9, 044.0, 044.9, 079.53, 279.10, 279.19, 795.71, 795.8, V08

090.0, 090.1, 090.2, 090.3, 090.40, 090.41, 090.42, 090.49, 090.5, 090.6, 090.7, 090.9, 091.0, 091.1, 091.2, 091.3, 091.4, 091.50, 091.51, 091.52, 091.61, 091.62, 091.69, 091.7, 091.81, 091.82, 091.89, 091.9, 092.0, 092.9, 093.0, 093.1, 093.20, 093.21, 093.22, 093.23, 093.24, 093.81, 093.82, 093.89, 093.9, 094.0, 094.1, 094.2, 094.3, 094.81, 094.82, 094.83, 094.84, 094.85, 094.86, 094.87, 094.89, 094.9, 095.0, 095.1, 095.2, 095.3, 095.4, 095.5, 095.6, 095.7, 095.8, 095.9, 096, 097.0, 097.1, 097.9, 098.0, 098.10, 098.11, 098.12, 098.13, 098.14, 098.15, 098.16, 098.17, 098.19, 098.2, 098.30, 098.31, 098.32, 098.33, 098.34, 098.35, 098.36, 098.37, 098.39,

098.40, 098.41, 098.42, 098.43, 098.49, 098.50, 098.51, 098.52, 098.53, 098.59, 098.6, 098.7, 098.81, 098.82, 098.83, 098.84, 098.85, 098.86, 098.89, 099.0, 099.1, 099.2, 099.3, 099.4, 099.40, 099.41, 099.49, 099.50, 099.51, 099.52, 099.53, 099.54, 099.55, 099.56, 099.59, 099.8, 099.9

291.81, 305.0, 303.0, 303.9, 655.4, 760.71, 291.1, 291.89, 291.2, 425.5, 291.0, 291.1, 291.2, 291.3, 291.82, 291.9, 291.5, 291.9, 291.4, $571.0,571.3,571.1,571.2,265.2,980.9,303.90,303.91,303.92,303.93,648.4,760.71, \mathrm{~V} 11.3$

$571.5,571.2,571.6,571$

585.6

$295.00,295.01,295.02,295.03,295.04,295.05,295.10,295.11,295.12,295.13,295.14,295.15,295.20,295.21,295.22,295.23$, 295.24, 295.25, 295.30, 295.31, 295.32, 295.33, 295.34, 295.35, 295.40, 295.41, 295.42, 295.43, 295.44, 295.45, 295.50, 295.51, $295.52,295.53,295.54,295.55,295.60,295.61,295.62,295.63,295.64,295.65,295.70,295.71,295.72,295.73,295.74,295.75$, 295.80, 295.81, 295.82, 295.83, 295.84, 295.85, 295.90, 295.91, 295.92, 295.93, 295.94, 295.95, 296.00, 296.01, 296.02, 296.03, $296.04,296.05,296.06,296.10,296.11,296.12,296.13,296.14,296.15,296.16,296.20,296.21,296.22,296.23,296.24,296.25$, 296.26, 296.30, 296.31, 296.32, 296.33, 296.34, 296.35, 296.36, 296.40, 296.41, 296.42, 296.43, 296.44, 296.45, 296.46, 296.50, $296.51,296.52,296.53,296.54,296.55,296.56,296.60,296.61,296.62,296.63,296.64,296.65,296.66,296.7,296.80,296.81$, 296.82, 296.89, 296.90, 296.99, 297.0, 297.1, 297.2, 297.3, 297.8, 297.9, 298.1, 298.2, 298.3, 298.4, 298.8, 298.9, 298.0, 300.4, $301.11,301.13,299.00,299.01,299.10,299.11,299.80,299.81,299.90,299.91,300.00,300.01,300.02,300.09,300.10,300.11$, $300.12,300.13,300.14,300.15,300.16,300.19,300.20,300.21,300.22,300.23,300.29,300.3,300.5,300.6,300.7,300.81$, 300.82 , 301.0, 301.10, 301.12, 301.20, 301.21, 301.22, 301.3, 301.4, 301.50, 301.51, 301.59, 301.6, 301.7, 301.81, 301.82, $301.83,301.84,301.89,301.9,307.40,307.41,307.42,307.43,307.44,307.45,307.47,307.48,307.49,307.80,307.81,307.89$, $307.9,308.0,308.1,308.2,308.3,308.4,308.9,309.81,312.30,312.31,312.32,312.33,312.34,312.35,312.39$ 


\section{Abbreviations}

ALT: Alanine aminotransferase; CDC: Centers for Disease Control and Prevention; EMR: Electronic medical record; HCV: Hepatitis C virus; HCV-Ab +: Hepatitis C virus antibody positive; HIV: Human Immunodeficiency Virus; ICD-9: International classification of diseases; IDU: Injection drug use; PCR: Polymerase chain reaction; RNA: Ribonucleic acid; USPS: United States preventive services task force.

\section{Competing interests}

The authors have no competing interests to report

\section{Authors' contributions}

WS analyzed the data and drafted the manuscript. BN designed the data analysis and drafted portions of the manuscript. MS collected data from chart reviews and approved the manuscript. JD assisted with study design and data collection and approved the manuscript. MLD designed the parent study and revised the manuscript. BS co-designed the study and revised the manuscript. AL designed the study, designed the parent study and revised the manuscript. All authors approved the manuscript.

\section{Acknowledgements}

Financial support: The Hepatitis C Assessment and Testing Project was funded by a Centers for Disease Control and Prevention contract via the Agency Health Care Research and Quality ACTION initiative to Boston University, contract HHSA2902006000012 T0\#4, the CTSA Grant UL1 RR025750 and KL2 RR025749 and TL1 RR025748 from the National Center for Research Resources (NCRR), a component of the National Institutes of Health $(\mathrm{NIH})$. This was supported by a subcontract from National Opinion Research Center (NORC) and the Centers for Disease Control and Prevention.

The findings and conclusions in this report are those of the authors and do not necessarily represent the official position of the Centers for Disease Control and Prevention.

\section{Funding}

Financial support: The Hepatitis C Assessment and Testing project was funded by a Centers for Disease Control and Prevention contract via the Agency Health Care Research and Quality ACTION initiative to Boston University, contract HHSA2902006000012 TO\#4. This analysis was supported by a subcontract from Centers for Disease Control and Prevention and National Opinion Research Center (NORC).

\section{Author details}

${ }^{1}$ Division of Hospital Medicine, 111 East 210th Street, Bronx 10467 NY, USA. ${ }^{2}$ Montefiore Medical Center, 111 East 210th Street, Bronx, NY 10467, USA. ${ }^{3}$ Division of General Internal Medicine, 111 East 210th Street, Bronx 10467 NY, USA. ${ }^{4}$ Section of Infectious Diseases, Department of Medicine, Boston University School of Medicine, 72 East Concord Street, Boston, MA 02118, USA. ${ }^{5}$ Division of Viral Hepatitis, Centers for Disease Control and Prevention, National Center for HIVNiral Hepatitis/STD/TB Prevention, 1600 Clifton Road, Atlanta, GA 30329, USA ${ }^{6}$ Department of Medicine, Montefiore Medical Center, 111 East 210th Street, Bronx, NY 10467, USA

\section{Received: 6 August 2015 Accepted: 19 November 2015} Published online: 01 December 2015

\section{References}

1. Denniston MM, Jiles RB, Drobeniuc J, Klevens RM, Ward JW, McQuillan GM, et al. Chronic hepatitis C virus infection in the United States, National Health and Nutrition Examination Survey 2003 to 2010. Annals of internal medicine. 2014;160(5):293-300.

2. Chak E, Talal AH, Sherman KE, Schiff ER, Saab S. Hepatitis C virus infection in USA: an estimate of true prevalence. Liver international : official journal of the International Association for the Study of the Liver. 2011;31(8):1090-101.

3. Rein DB, Wittenborn JS, Weinbaum CM, Sabin M, Smith BD, Lesesne SB. Forecasting the morbidity and mortality associated with prevalent cases of pre-cirrhotic chronic hepatitis $C$ in the United States. Digestive and liver disease : official journal of the Italian Society of Gastroenterology and the Italian Association for the Study of the Liver. 2011;43(1):66-72.

4. Manns MP, McHutchison JG, Gordon SC, Rustgi VK, Shiffman M, Reindollar R, et al. Peginterferon alfa-2b plus ribavirin compared with interferon alfa-2b plus ribavirin for initial treatment of chronic hepatitis C: a randomised trial. Lancet. 2001;358(9286):958-65.

5. Fried MW, Shiffman ML, Reddy KR, Smith C, Marinos G, Goncales FL, Jr., et al Peginterferon alfa-2a plus ribavirin for chronic hepatitis $C$ virus infection. NEnglJMed. 2002;347(13):975-82.

6. Hadziyannis SJ, Sette H, Jr., Morgan TR, Balan V, Diago M, Marcellin P, et al. Peginterferon-alpha2a and ribavirin combination therapy in chronic hepatitis $\mathrm{C}$ : a randomized study of treatment duration and ribavirin dose. Ann Intern Med. 2004;140(5):346-55.

7. Strader DB, Wright T, Thomas DL, Seeff LB. Diagnosis, management, and treatment of hepatitis C. Hepatology. 2004;39(4):1147-71.

8. Ghany MG, Strader DB, Thomas DL, Seeff LB. Diagnosis, management, and treatment of hepatitis C: an update. Hepatology. 2009;49(4):1335-74.

9. Recommendations for prevention and control of hepatitis $\mathrm{C}$ virus (HCV) infection and HCV-related chronic disease. Centers for Disease Control and Prevention. MMWR Recomm Rep. 1998;47(RR-19):1-39.

10. EASL International Consensus Conference on hepatitis C. Paris, 26-27 February 1999. Consensus statement. J Hepatol. 1999;30(5):956-61.

11. Galmiche JP. French consensus conference on hepatitis C: screening and treatment. Gut. 1998;42(6):892-8.

12. National Institutes of Health Consensus Development Conference Statement: Management of hepatitis C:2002-June 10-12, 2002. Hepatology. 2002;36:s3-s20.

13. Southern WN, Drainoni ML, Smith BD, Christiansen CL, McKee D, Gifford AL, et al. Hepatitis $C$ testing practices and prevalence in a high-risk urban ambulatory care setting. Journal of viral hepatitis. 2011;18(7):474-81.

14. Roblin DW, Smith BD, Weinbaum CM, Sabin ME. HCV screening practices and prevalence in an MCO, 2000-2007. The American journal of managed care. 2011;17(8):548-55.

15. Spradling PR, Rupp L, Moorman AC, Lu M, Teshale EH, Gordon SC, et al. Hepatitis $B$ and $C$ virus infection among 1.2 million persons with access to care: factors associated with testing and infection prevalence. Clinical infectious diseases : an official publication of the Infectious Diseases Society of America. 2012;55(8):1047-55.

16. Smith BD, Morgan RL, Beckett GA, Falck-Ytter $Y$, Holtzman D, Teo CG, et al. Recommendations for the identification of chronic hepatitis $C$ virus infection among persons born during 1945-1965. MMWR. Recommendations and reports : Morbidity and mortality weekly report. Recommendations and reports / Centers for Disease Control. 2012;61(RR-4):1-32.

17. Smith BD, Beckett GA, Yartel A, Holtzman D, Patel N, Ward JW. Previous exposure to HCV among persons born during 1945-1965: prevalence and predictors, United States, 1999-2008. American journal of public health. 2014;104(3):474-81.

18. Smith BD, Patel N, Beckett GA, Jewett A, Ward JW. Hepatitis C virus antibody prevalence, correlates and predictors among persons born from 1945 through 1965, United States, 1999-2008. Hepatology. 2011;54:4(Suppl): 554A-555A.

19. Tomaszewski KJ, Deniz B, Tomanovich P, Graham CS. Comparison of current US risk strategy to screen for hepatitis $C$ virus with a hypothetical targeted birth cohort strategy. American journal of public health. 2012;102(11):e101-106.

20. Smith BD, Yartel AK. Comparison of hepatitis $C$ virus testing strategies: birth cohort versus elevated alanine aminotransferase levels. American journal of preventive medicine. 2014;47(3):233-41.

21. Drainoni ML, Litwin AH, Smith BD, Koppelman EA, McKee MD, Christiansen CL, et al. Effectiveness of a risk screener in identifying hepatitis $C$ virus in a primary care setting. American journal of public health. 2012;102(11):e115-121.

22. Litwin AH, Smith BD, Drainoni ML, McKee D, Gifford AL, Koppelman E, et al. Primary care-based interventions are associated with increases in hepatitis C virus testing for patients at risk. Digestive and liver disease : official journal of the Italian Society of Gastroenterology and the Italian Association for the Study of the Liver. 2012;44(6):497-503.

23. Thomas DL, Cannon RO, Shapiro CN, Hook III EW, Alter MJ, Quinn TC. Hepatitis $C$, hepatitis $B$, and human immunodeficiency virus infections among non-intravenous drug-using patients attending clinics for sexually transmitted diseases. J Infect Dis. 1994;169(5):990-5.

24. Thomas DL, Zenilman JM, Alter HJ, Shih JW, Galai N, Carella AV, et al. Sexual transmission of hepatitis $C$ virus among patients attending sexually transmitted diseases clinics in Baltimore-an analysis of 309 sex partnerships. J Infect Dis. 1995;171(4):768-75.

25. Rosman AS, Waraich A, Galvin K, Casiano J, Paronetto F, Lieber CS. Alcoholism is associated with hepatitis C but not hepatitis B in an urban population. Am J Gastroenterol. 1996;91(3):498-505. 
26. Rosman AS, Paronetto F, Galvin K, Williams RJ, Lieber CS. Hepatitis C virus antibody in alcoholic patients. Association with the presence of portal and/or lobular hepatitis. Archives of internal medicine. 1993;153(8):965-9.

27. Schaefer M, Capuron L, Friebe A, Diez-Quevedo C, Robaeys G, Neri S, et al. Hepatitis $C$ infection, antiviral treatment and mental health: a European expert consensus statement. J Hepatol. 2012;57(6):1379-90.

28. Raja M, Azzoni A, Pucci D. Characteristics of HCV positive patients in an Italian urban psychiatric unit. Clinical practice and epidemiology in mental health : CP \& EMH. 2006;2:26.

29. Prati D, Taioli E, Zanella A, Della TE, Butelli S, Del VE, et al. Updated definitions of healthy ranges for serum alanine aminotransferase levels. Ann Intern Med. 2002:137(1):1-10.

30. Pratt DS, Kaplan MM. Evaluation of abnormal liver-enzyme results in asymptomatic patients. N Engl J Med. 2000;342(17):1266-71.

31. Clinical Classifications Software. Healthcare Cost and Utilization Project (HCUP) website Of the Agency for Healthcare Quality and Research (AHRQ). 2007. http://www.hcup-us.ahrq.gov/toolssoftware/ccs/ccs.jsp.

32. Swan D, Long J, Carr O, Flanagan J, Irish H, Keating S, et al. Barriers to and facilitators of hepatitis $C$ testing, management, and treatment among current and former injecting drug users: a qualitative exploration. AIDS patient care and STDs. 2010;24(12):753-62.

33. Shakil AO, Conry-Cantilena C, Alter HJ, Hayashi P, Kleiner DE, Tedeschi V, et al. The Hepatitis C Study Group, et al. Volunteer blood donors with antibody to hepatitis C virus: clinical, biochemical, virologic, and histologic features. Annals of internal medicine. 1995;123(5):330-7.

34. Seeff LB. Natural history of hepatitis C. Hepatology. 1997;26(3 Suppl 1):21S-8S

35. Hagan LM, Schinazi RF. Best strategies for global HCV eradication. Liver international : official journal of the International Association for the Study of the Liver. 2013;33 Suppl 1:68-79.

36. Rein DB, Smith BD, Wittenborn JS, Lesesne SB, Wagner LD, Roblin DW, et al. The cost-effectiveness of birth-cohort screening for hepatitis $C$ antibody in U.S. primary care settings. Annals of internal medicine. 2012:156(4):263-70.

37. McGarry LJ, Pawar VS, Panchmatia HR, Rubin JL, Davis GL, Younossi ZM, et al. Economic model of a birth cohort screening program for hepatitis $\mathrm{C}$ virus. Hepatology. 2012;55(5):1344-55.

\section{Submit your next manuscript to BioMed Central and we will help you at every step:}

- We accept pre-submission inquiries

- Our selector tool helps you to find the most relevant journal

- We provide round the clock customer support

- Convenient online submission

- Thorough peer review

- Inclusion in PubMed and all major indexing services

- Maximum visibility for your research 